\title{
Planos privados individuais de saúde: o consumidor ainda tem poder de escolha?
}

Individual health plans: Does the consumer still have power of choice?

Planes de salud individuales: ¿El consumidor todavía tiene poder de elección?

Gilka Lopes Moreira Antonio'1

RESUMO. Objetivo: Estudou-se o fenômeno da redução da oferta de planos de saúde privados de assistência médica individuais/familiares. Metodologia: Tratou-se de estudo com abordagem quali-quantitativa, descritivo e explicativo, realizado por intermédio de procedimentos de pesquisa documental e bibliográfica. Resultados: Os planos individuais e coletivos têm características diferentes; as regras aplicáveis aos contratos individuais são mais rígidas; o mercado de planos individuais está altamente concentrado; há pouca oferta desse tipo de produto pelas operadoras, sobretudo de abrangência nacional. Conclusão: A redução da oferta de planos individuais/familiares e a comercialização de produtos mais restritos afetam o direito à saúde visto que reduz o poder de escolha do consumidor, as possibilidades de mobilidade, e dificulta a contratação de planos por aqueles que estão fora do mercado de trabalho formal, principalmente os idosos.

Palavras-chave: Saúde Suplementar. Assistência Médica. Regulação e Fiscalização em Saúde. Direito à saúde.

ABSTRACT. Objective: The article studied the supply reduction of individual health plans that include medical assistance. Methodology: The study had a qualitative and quantitative approach. It was realized in an explanatory and descriptive way, through procedures of documentary and bibliographic research. Results: The results show that: individual and group health plans have different characteristics and there are stricter rules applicable to the individual plans; the supply of this product is low; this market is concentrated; there are few options of national coverage plans. Conclusion: The supply reduction of individual health plans that include medical assistance affects the right to health, because the supplemental health users don't have power of choice or possibilities to move to another provider. It is more difficult for elderly users.

Keywords: Supplemental Health. Medical Assistance. Health Care Coordination and Monitoring. Right to health.

RESUMEN. Objetivo: El artículo estudia la reducción de la oferta de planes de salud individuales que incluyen asistencia médica. Metodología: Se trató de estudio descriptivo, explicativo, cualitativo y cuantitativo, hecho a través de procedimientos de investigación documental y bibliográfica. Resultados: Los resultados muestran que: los planes de salud individuales y de grupo tienen características distintas; las normas aplicables a los contratos son más rígidas; el mercado está concentrado; hay escasez de oferta de este producto. Conclusión: La reducción de la oferta de planes de salud individuales que incluyen asistencia médica perjudica el derecho a la salud, porque los usuarios de la salud

\footnotetext{
${ }^{1}$ Graduada em Administração pela Universidade Federal de Mato Grosso, Técnica em regulação de saúde suplementar na Agência Nacional de Saúde Suplementar - Distrito Federal. Brasil. E-mail: gilkalopes@gmail.com
} 
complementaria no tienen poder de elección y no puedan cambiar a otra operadora. Los consumidores ancianos tienen más dificultades con la contratación de planes de salud.

Palabras-Ilave: Salud Complementaria. Asistencia Médica. Regulación y Fiscalización en Salud. Derecho a la salud.

\section{Introdução}

No Brasil, a política de saúde vigente é caracterizada pelo mix público-privado, ou seja, pela convivência - nem sempre harmônica - entre formas públicas e privadas de assistência, acesso, financiamento e produção das ações de saúde. Esse formato institucional híbrido foi sendo configurado a partir do início do século $X X$, com a organização da previdência e dos serviços médicos em torno de trabalhadores assalariados. (1)

Embora a Constituição Federal de 1988 (2) tenha reconhecido o direito à saúde e delineado as principais diretrizes para a criação do Sistema Único de Saúde (SUS), de acesso gratuito e universal, a iniciativa privada, que à época já se encontrava consolidada e atuando à margem de qualquer regulamentação governamental (1), foi autorizada a atuar na assistência à saúde, mediante o controle e a fiscalização do Poder Público, seja por meio da participação de forma complementar aos serviços ofertados pelo SUS, seja ofertando planos e seguros privados de saúde (saúde suplementar). (3)

O seguinte arcabouço normativo foi constituído para a regulação do setor de saúde suplementar: Lei no 9.656/1998 (4), que estabeleceu regras gerais para o funcionamento do mercado de planos de saúde; Lei no 9.961/2000 (5), que instituiu a Agência Nacional de Saúde Suplementar (ANS) como agência reguladora desse mercado; Lei nํ 8.078/1990 (Código de Defesa do Consumidor) (6), que se aplica de forma subsidiária na solução de controvérsias que envolvem as relações entre operadoras e seus contratantes; e normas infralegais expedidas pela ANS.

A regulação estatal alcança todas as pessoas jurídicas de direito privado que atuam na operação e na administração de planos de saúde de assistência médica e/ou odontológica: cooperativas odontológicas, empresas de odontologia de grupo, empresas de medicina de grupo, cooperativas médicas, autogestões, empresas de filantropia, administradoras de benefícios e seguradoras especializadas em saúde (4) (7).

Os produtos ofertados pelas operadoras comerciais, de acordo com a forma de contratação, podem ser: (a) individuais/familiares, quando o indivíduo adquire diretamente o produto com uma operadora para si ou para seu grupo familiar; ou (b) coletivos, quando a 
contratação é feita por uma pessoa jurídica, e a adesão do indivíduo depende da existência de um vínculo empregatício (coletivo empresarial) ou associativo, classista, sindical (coletivo por adesão) $)^{2}$. (8) (9)

De acordo com essa classificação, o órgão regulador aplica regras diferentes aos contratos, o que afeta o comportamento das operadoras e, consequentemente, os usuários de seus serviços.

Como um efeito de feedback das políticas de saúde e da caracterização da assistência privada como "um benefício vinculado às relações de trabalho", o setor sempre registrou o predomínio dos planos coletivos. (1)

Após os anos 80, no entanto, as operadoras expandiram sua atuação para a assistência médica supletiva individual para atender à demanda das classes mais abastadas, impactadas pelos custos crescentes da medicina privada (1), de modo que, em 2004, quase $25 \%$ dos contratos de planos privados de saúde eram individuais/familiares. Todavia, nos anos seguintes, passou-se a registrar um recuo na proporção de planos individuais, em relação aos coletivos.

Um estudo realizado pelo Conselho Nacional de Secretários de Saúde (CONASS), em 2008, revelou a acentuação da "coletivização" do setor de saúde suplementar, ou seja, "a redução dos planos individuais/ familiares e o aumento de planos coletivos" (10). A publicação ressaltou que o crescimento dos planos coletivos se devia não somente à melhora do nível de emprego formal no país, registrada desde o ano de 2002 (11), mas também à menor oferta de produtos individuais, em virtude da maior rigidez da regulamentação sobre eles.

Assim, o objetivo do artigo foi estudar o fenômeno da redução na oferta de planos individuais de saúde pelas operadoras de planos privados de saúde, a partir de dados atuais do setor, em busca das causas desse fenômeno, dos principais impactos para os usuários dos serviços da saúde suplementar e das perspectivas futuras, partindo-se da hipótese de que tal redução se deve à concentração dos esforços regulatórios sobre os planos individuais.

\footnotetext{
2 As empresas de autogestão são proibidas de comercializar planos individuais/familiares e as administradoras de benefícios não podem executar atividades típicas da operação de planos privados, podendo atuar apenas na proposição de contratos coletivos (como estipulantes) ou na prestação de atividades de apoio às operadoras, relacionadas aos planos coletivos (9).
} 


\section{Metodologia}

Tratou-se de pesquisa com abordagem quali-quantitativa, de natureza aplicada, descritiva e explicativa, com a utilização de ferramentas da pesquisa documental e bibliográfica. (12)

Para a descrição do fenômeno, foram obtidas no sítio da ANS, na aba "Legislação" (http://www.ans.gov.br/legislacao/busca-de-legislacao), as seguintes leis e normas infralegais, relacionadas à diferenciação dos planos individuais e coletivos: Lei $\mathrm{n}^{\circ}$ 9.656/1998, Lei no 9.961/2000, Resoluções Normativas (RN's) n 195/2009, nº 309/2012, nº 186/2009 e no 196/2009, e Resolução do Conselho de Saúde Suplementar (CONSU) no 19/1999. A pesquisa foi realizada no período de agosto a outubro de 2017.

No mesmo período, foram analisados e tratados os dados de acesso livre, divulgados no sítio da ANS, na aba "Dados do Setor" (http://www.ans.gov.br/perfil-do-setor/dados-eindicadores-do-setor), sobre a evolução do mercado de planos privados de saúde no período entre 2000 e 2017, divulgados por meio dos Cadernos de Informação de janeiro/2007 e de junho/2017, do Atlas Econômico-Financeiro (2016), dos Dados Gerais do Setor e da Sala de Situação. Verificaram-se, ainda, os percentuais de reajuste aplicados aos planos coletivos disponibilizados no sítio da ANS, na aba "Espaço do Consumidor" (http://www.ans.gov.br/planos-de-saude-e-operadoras/espaco-do-consumidor).

Estudos divulgados nos sítios do Instituto de Pesquisa Econômica Aplicada (IPEA) e do Instituto de Defesa do Consumidor (IDEC) sobre o mercado de planos individuais e coletivos foram empregados na pesquisa.

A pesquisa abordou apenas os planos de assistência médica, excluindo-se, portanto, os planos exclusivamente odontológicos e as operadoras que comercializam apenas esse tipo de produto (cooperativas odontológicas, odontologia de grupo). O levantamento dos dados sobre as operadoras de planos de assistência médica também desconsiderou as operadoras da modalidade de autogestão, já que elas são proibidas de ofertar planos individuais. Os planos coletivos por adesão e coletivos empresariais foram designados, no texto, apenas como planos coletivos.

Tendo em vista que o assunto da redução da oferta de planos de saúde individuais estava em pauta, na mídia, durante o desenvolvimento da pesquisa, entre os meses de agosto a outubro de 2017, algumas reportagens jornalísticas foram utilizadas para a atualização e contextualização do fenômeno, por noticiarem os impactos sofridos pelos 
consumidores da saúde suplementar. Os artigos e reportagens foram acessados por meio da base de dados de notícias do Google, com os descritores "planos individuais de saúde", e "dificuldade na contratação de planos individuais de saúde", e retirados dos portais Terra, Correio Braziliense, Empresa Brasil de Comunicação, Folha UOL, Folha PE, G1, O Globo e Estadão.

Por fim, também se utilizou o conteúdo das discussões que estão sendo empreendidas no Congresso Nacional sobre a matéria: Projeto de Lei no 7.419/2006 (Parecer do Relator apresentado em 18/10/2017) e Projeto de Lei do Senado no 76/2017 (proposição e justificação), documentos que estão disponíveis, respectivamente, nos sítios da Câmara dos Deputados (http://www.camara.gov.br/proposicoesWeb) e do Senado Federal (https://www25.senado.leg.br/web/atividade/materias/-/materia/128532).

\section{Resultados}

A análise comparada dos dados disponíveis nos Cadernos de Informação da Agência Nacional de Saúde Suplementar (ANS) revela que, no período de dezembro de 2000 a julho de 2017, o número de vidas vinculadas a planos individuais de assistência médica subiu de 5.658.666 para 9.247.147 (crescimento de 63,42\%), enquanto o número de vidas vinculadas a contratos coletivos passou de 11.321 .904 para 37.942 .063 (crescimento de $235,12 \%)^{3}$. (13) (14) (15)

Desde dezembro de 2004, quando os planos individuais chegaram a representar $24,66 \%$ do setor de assistência médica, têm-se registrado sucessivas reduções na proporção de planos individuais, em comparação com o de planos coletivos, conforme ilustrado no gráfico 1.

\footnotetext{
${ }^{3}$ Desconsiderou-se, aqui, o número de contratos com tipo não identificado, que era de 14.180.911 (dezembro/2000) e diminuiu para 191.986 (julho/2017). A quantidade de vínculos com tipo de contratação não identificado vem diminuindo com a melhoria da qualidade das informações enviadas pelas operadoras, com o aperfeiçoamento dos sistemas de informação da ANS e com a definição normativa mais precisa acerca dos tipos de contratação.
} 
Gráfico 1 - Proporção de planos individuais e coletivos (evolução de 2004-2017).

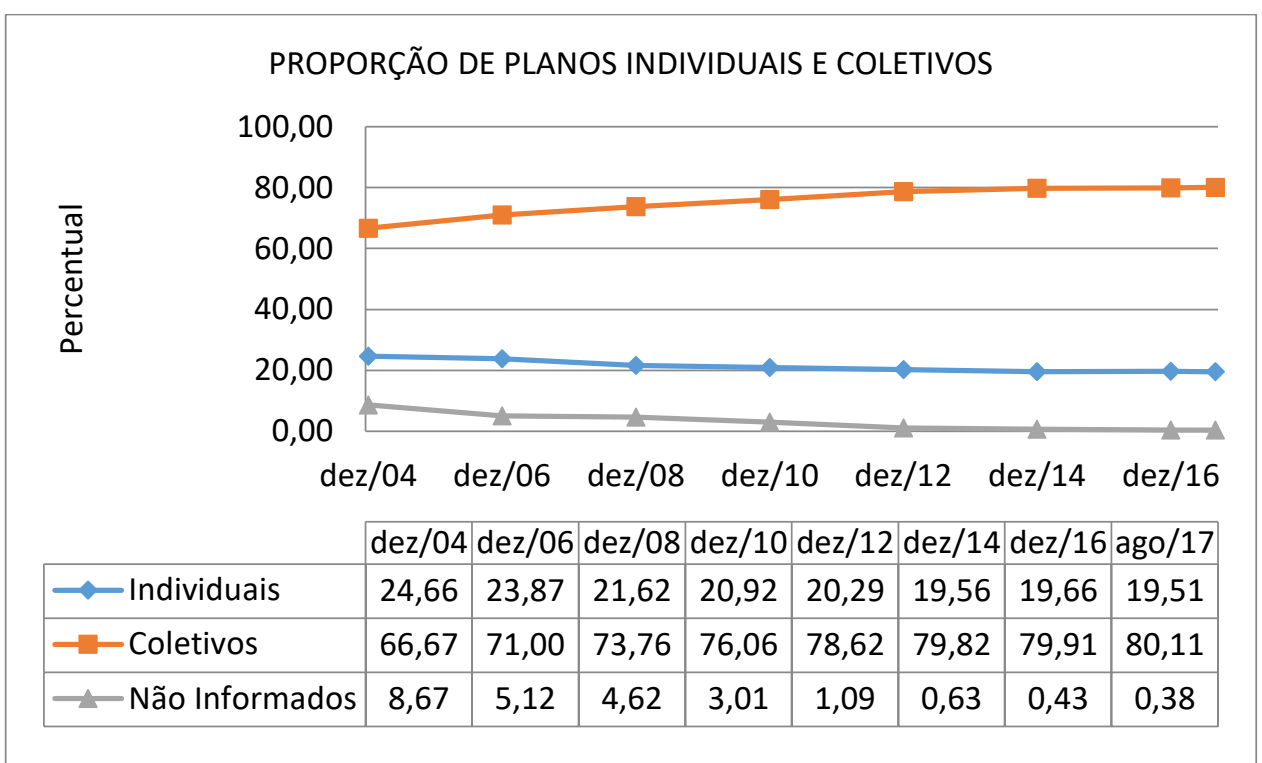

Fonte: Elaborado pela autora a partir dos dados disponíveis na Sala de Situação (14) e nos Cadernos de Informação 01/2007 (15) e 06/2017 (13).

Segundo dados de agosto de 2017, apenas 19,51\% dos beneficiários da saúde suplementar (assistência médica) estão vinculados a planos individuais (13), e quase $20 \%$ das operadoras comerciais que dispõem de algum produto de assistência médica não ofertam mais qualquer plano individual/familiar, mantendo, assim, apenas a carteira residual desse tipo de contrato. (14)

No período de março de 2016 a março de 2017, quando o setor registrou perda no número total de usuários, essa foi mais acentuada no segmento de planos de assistência médica individual, em relação aos coletivos, com taxas de variação de -2,23 e -1,90, respectivamente ${ }^{4}$. (14)

No gráfico 2, observa-se que, no período entre janeiro de 2007 e julho de 2017, o mercado de planos de assistência médica de contratação coletiva cresceu $47,21 \%$, enquanto o de planos individuais/familiares cresceu $12,34 \%$.

\footnotetext{
${ }^{4}$ Desde o mês novembro de 2014, quando o setor atingiu o maior número de vidas vinculadas a planos de assistência médica (50.369.062), até agosto de 2017, houve redução de 6,08\% no total de contratos, o que representa uma perda de mais de três milhões de contratos.
} 
Gráfico 2 - Crescimento do mercado de planos de assistência médica individuais e coletivos (número de vidas)

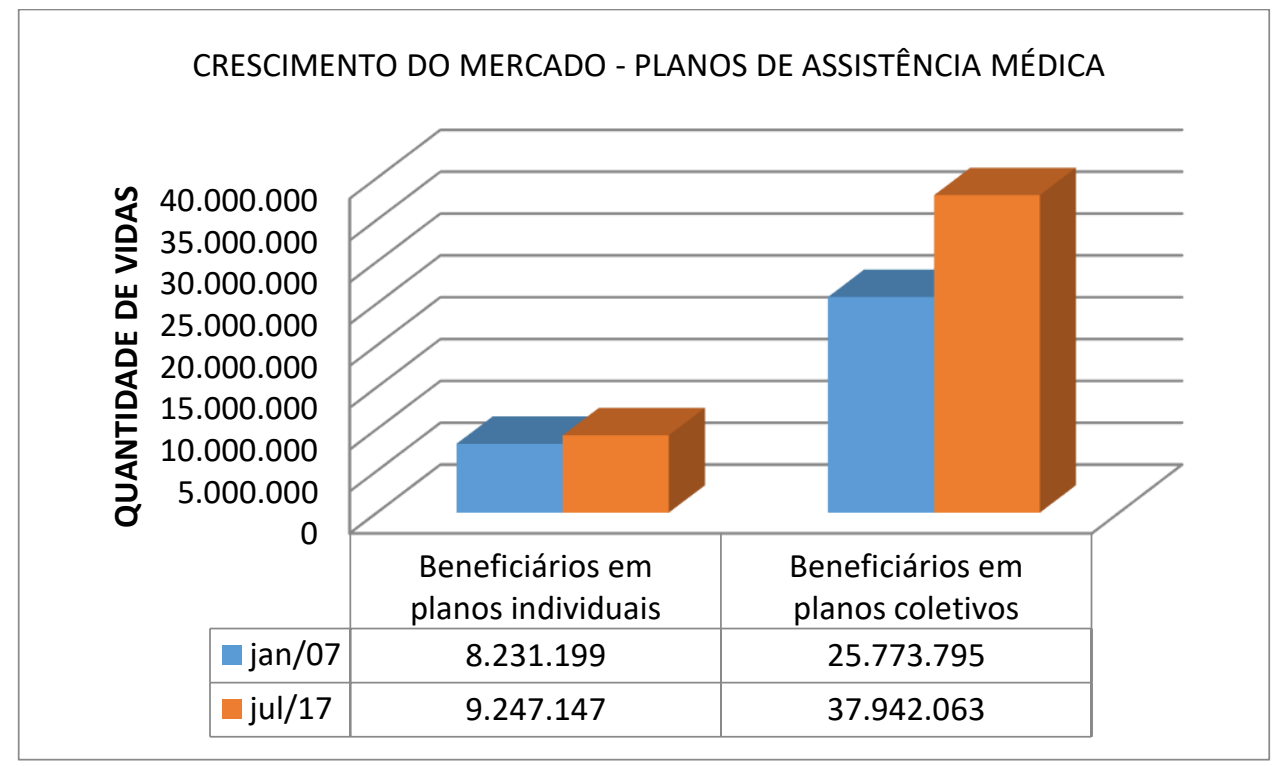

Fonte: Elaborado pela autora a partir dos dados disponíveis na Sala de Situação (14) e nos Cadernos de Informação 01/2007 (15) e 06/2017 (13).

No mesmo período, o mercado se tornou mais concentrado em termos de operadoras de planos de saúde (OPS) ativas. Houve redução de mais de $47 \%$ no número total de operadoras, restando apenas 612 das 1.164 operadoras comerciais que existiam em 2007 (excetuando-se as autogestões). (13) (14) (15)

Essa informação é corroborada na $12^{\text {a }}$ edição do Atlas Econômico-Financeiro da Saúde Suplementar, publicado pela ANS, que analisou 96 regiões que representam os mercados relevantes para a saúde suplementar, e concluiu que o mercado apresenta nível de concentração preocupante na maioria delas. (16)

No segmento de planos coletivos, detectou-se que, em $17 \%$ das regiões, o mercado está altamente concentrado; que 37\% apresentam um mercado moderadamente concentrado; e que $46 \%$ delas têm o mercado desconcentrado. Apesar de não ser o nível ideal de concorrência, os dados demonstram que ainda há competição entre operadoras pelo nicho dos planos coletivos. (16)

Em contrapartida, as informações do Atlas Econômico-Financeiro indicam que, no campo dos planos individuais, a competição entre operadoras é baixíssima, à medida que esse mercado está altamente concentrado em $91 \%$ dessas regiões, moderadamente 
concentrado em 6\% delas e desconcentrado em apenas 3\% (São Paulo-SP, Guarulhos-SP e Rio de Janeiro-RJ). (16)

A própria agência reconheceu ter encontrado um setor "mais concentrado do que parecia à primeira vista", tendo em vista que o nível "altamente concentrado" antecede a condição de monopólio puro, hipótese em que uma única operadora concentra $100 \%$ dos usuários daquela região. (16)

Dados disponíveis na Sala de Situação da ANS apontam, ainda, para a ausência de oferta de planos individuais pelas seguradoras especializadas em saúde que, embora tenham iniciado suas transações no ramo da saúde a partir da captura da clientela individual, deixaram de comercializar planos desse segmento (1), conforme ilustrado no gráfico 3.

Gráfico 3 - Operadoras comerciais por modalidade (assistência médica) x Comercialização de planos individuais/familiares: setembro/2017

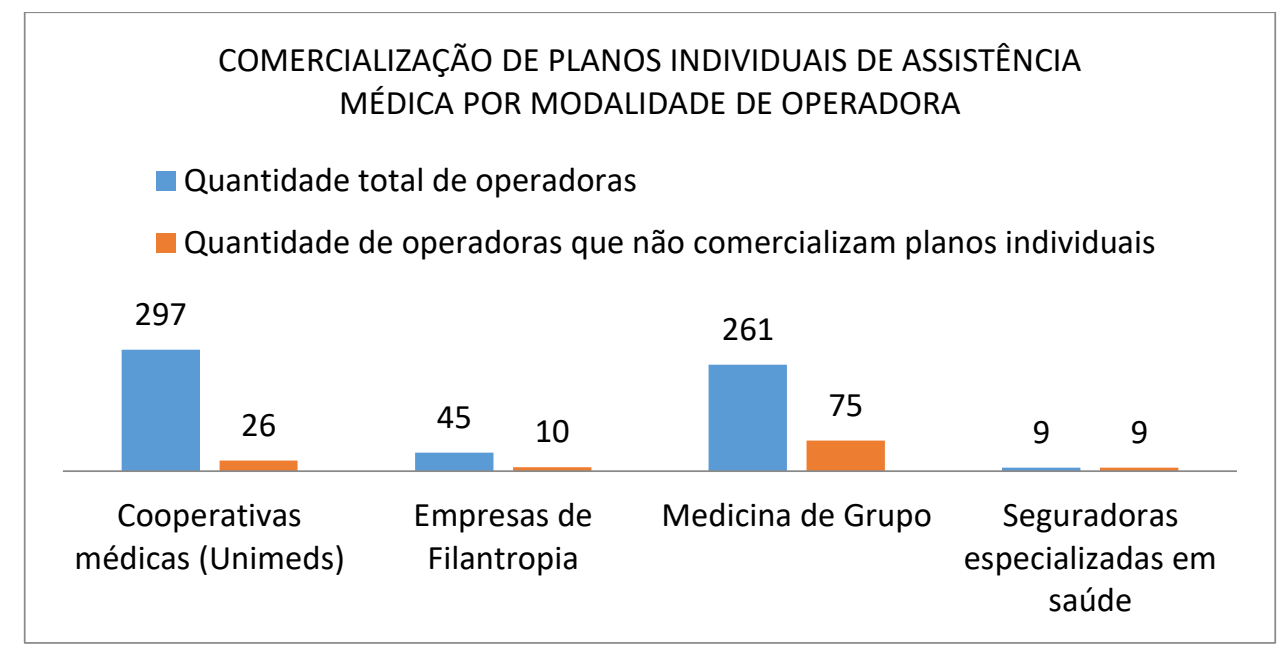

Fonte: Elaborado pela autora a partir dos dados da Sala de Situação. (14)

Conquanto $80,4 \%$ das operadoras comerciais ainda ofertem algum produto de assistência médica individual/familiar, de forma geral, constatou-se uma predominância de produtos com menor área de abrangência, notadamente produtos restritos a um "grupo de municípios", de acordo com a relação de "planos por operadora", disponível no sítio da ANS. 
Gráfico 4 - Produtos individuais de assistência médica ativos (por área de abrangência): setembro/2017.

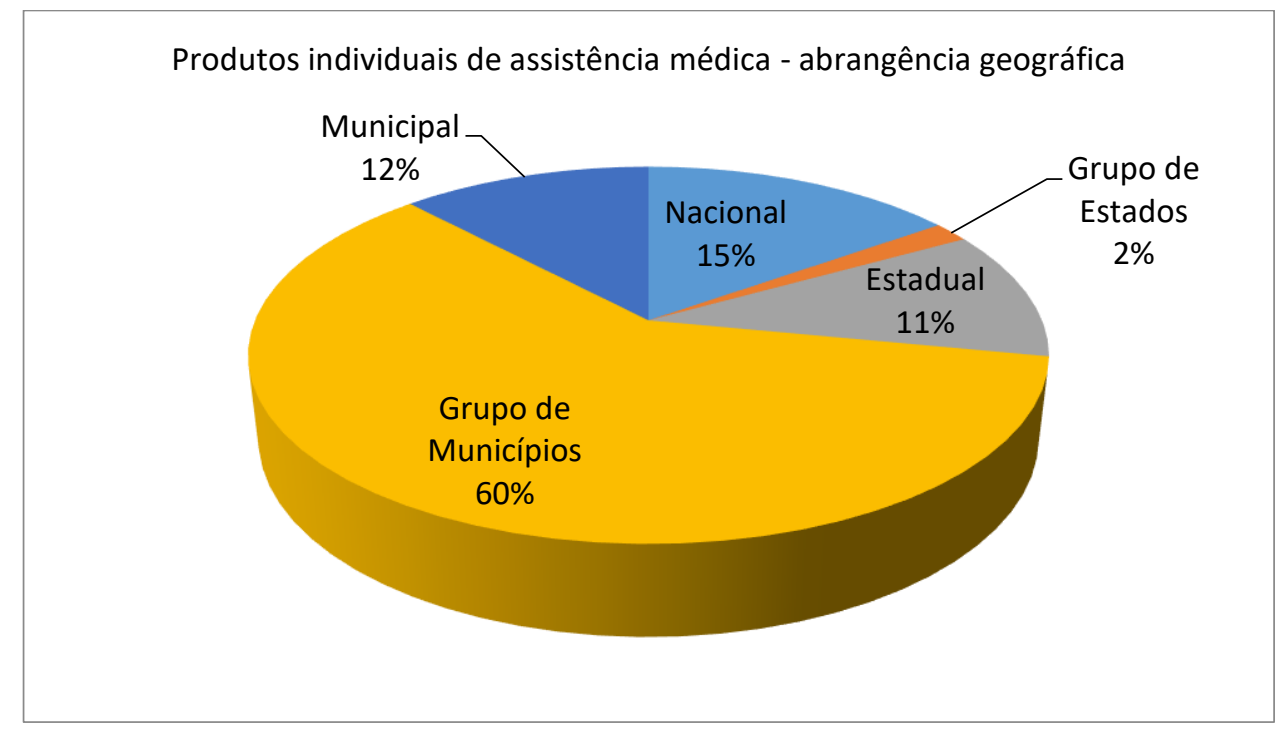

Fonte: Elaborado pela autora a partir dos Dados Gerais - Planos por operadora (17)

O filtro desses dados também revela que nenhum plano individual/familiar de assistência médica com abrangência nacional está sendo comercializado pelas seis maiores operadoras em atividade no país, que concentram mais de 30\% dos beneficiários do setor (Amil, Bradesco, Notre Dame, Hapvida, Sul América e Central Nacional Unimed). (14) (17)

Além disso, constatou-se que os 611 produtos individuais/familiares de assistência médica com abrangência nacional e que incluem a segmentação hospitalar são comercializados por apenas 144 operadoras (do total de 612 operadoras comerciais em atividade). Desse universo, 142 delas são cooperativas do sistema Unimed (o que significa $47,8 \%$ das cooperativas Unimed - que não competem entre si), e as outras duas são da modalidade medicina de grupo - PAME Assistência (venda no Rio de Janeiro e Distrito Federal), Humana (venda em alguns estados do Nordeste). (17)

\section{Discussão}

A análise dos dados confirma a acentuação da coletivização do setor de saúde suplementar (assistência médica), a pouca oferta de planos individuais por operadoras de grande porte, a menor competição entre as operadoras pelo mercado de planos individuais, o abandono desse segmento pelas seguradoras especializadas em saúde e, principalmente, 
a escassez na oferta de planos individuais com alcance geográfico mais amplo (abrangência nacional).

O menor interesse das operadoras de planos de saúde na comercialização de planos individuais/familiares tem sido atribuído à maior interferência estatal sobre esse tipo de contrato, no que tange à rescisão contratual e ao reajuste anual (10) (11), já que os consumidores individuais não têm o mesmo poder de barganha e a representatividade dos contratantes grupais (coletivos). (18)

Isso porque, enquanto a legislação protege o consumidor de plano individual/familiar de cancelamentos contratuais unilaterais e injustificados (4), os beneficiários de planos coletivos podem ser excluídos do plano por atraso no pagamento, de acordo com o período discricionariamente estabelecido em cada instrumento contratual, podendo também ficar desassistidos sem prévio aviso da operadora mesmo em situação de total adimplência, caso haja o rompimento do contrato com o estipulante. (9)

Igualmente, há maior regulamentação da ANS sobre os planos individuais/familiares no que diz respeito aos reajustes anuais aplicados às mensalidades, pois a agência reguladora divulga um percentual máximo para a majoração das contraprestações desses planos, calculado a partir da média do reajuste anual aplicado pelas operadoras aos contratos coletivos. (19)

No caso dos planos coletivos, entretanto, as mensalidades podem ser reajustadas livremente pelas operadoras, as quais estão obrigadas apenas a informar os percentuais aplicados à ANS (20), e a agrupar os seus contratos coletivos com menos de trinta beneficiários, para calcular esse reajuste. (21)

A metodologia de reajuste adotada pela ANS tem sido criticada por instituições de defesa do consumidor, beneficiários e outros atores setoriais pelo fato de não considerar os custos da carteira de planos individuais, que tem características próprias (19); por deixar "desprotegidos" os consumidores de planos coletivos, porquanto grande parte deles não possui poder real de barganha; e por permitir que, até mesmo os planos individuais sejam reajustados em percentuais acima dos índices oficiais de inflação. (22)

Em que pese ter realizado diversos estudos sobre metodologias alternativas de reajuste, entre 2009 e 2014, a ANS mantém esse modelo até os dias atuais (23). A Agência sustenta que "não estipula o percentual de reajuste dos planos coletivos porque as empresas contratantes exercem seu poder de negociação com as operadoras de planos de saúde"; 
que protege os pequenos contratantes coletivos dos aumentos abusivos ao exigir que eles sejam agrupados para fins de cálculo de reajuste; e que "é um erro comparar e induzir à comparação do reajuste de planos de saúde ao índice geral de inflação", sob o argumento de que "o índice de planos de saúde não é um índice de preços", e sim um "índice de valor", já que ele é "composto pela variação da frequência de utilização de serviços, da incorporação de novas tecnologias e pela variação dos custos em saúde". (18)

Verifica-se, portanto, que a menor oferta de planos individuais pode, sim, ser um efeito colateral da maior regulamentação sobre eles, já que, ao comercializarem predominante ou exclusivamente planos coletivos, as OPS aumentam sua liquidez, mediante a possibilidade de definirem reajustes mais livremente, e evitam o "envelhecimento" de suas carteiras, pois a flexibilidade para o cancelamento unilateral dos contratos coletivos torna esses vínculos mais precários e não as obriga a continuar com um beneficiário ao longo de sua vida.

Contudo, outros fatores contribuem para o desinteresse das operadoras pelas carteiras individuais de planos de saúde.

No Brasil, observa-se uma grande orquestração de discurso sobre o oferecimento e patrocínio de planos de saúde a trabalhadores do setor privado (1) e também a servidores públicos (24). O plano de saúde passou a ser considerado como um benefício de forte apelo para atração de pessoal e as empresas são incentivadas a disponibilizá-lo aos seus funcionários, tanto pela ação sindical quanto pelo próprio governo, que ressarce os servidores públicos uma parte da mensalidade custeada por eles (24), e possibilita a contabilização do gasto das empresas com o plano de saúde dos empregados como despesa operacional, na apuração do lucro real, reduzindo, assim, o valor do Imposto de Renda da Pessoa Jurídica (1). O crescimento desse mercado flutua também em função do nível de emprego da população. (11)

Os preços finais ao beneficiário são menores nos planos coletivos em razão da participação da empresa empregadora, das possibilidades de ganhos de escala pela operadora (1) (11), da maior concentração de população economicamente ativa/saudável, e da menor incidência de idosos, que demandam tratamentos especializados e mais longos. (25)

Por outro lado, os planos individuais apresentam preços mais altos, por apresentarem maior sinistralidade (1), e por não haver o compartilhamento de riscos, nem a possibilidade de aplicação de reajustes personalizados, frente ao aumento dos custos assistenciais. (26) 
Seu crescimento é limitado porque dependem diretamente do poder aquisitivo da população (1), estando, por conseguinte, mais sujeitos a crises de subconsumo, decorrentes da combinação de preços crescentes com salários decrescentes (26), conquanto também haja incentivo governamental para o seu consumo, por meio da possibilidade de dedução fiscal no pagamento do Imposto de Renda da Pessoa Física. (1)

Diante da maior vantajosidade da comercialização de planos coletivos, as operadoras vêm lançando mão de algumas estratégias, como a "coletivização" de vínculos que, à primeira vista, seriam considerados individuais, ou seja, a celebração de contratos coletivos com grupos formados por duas ou mais pessoas, inclusive com microempreendedores individuais, que embora não tenham qualquer poder de negociação frente à operadora, são atraídos por preços de mensalidade inicialmente menores. (27) (28) (29)

Vale ressaltar, no entanto, que, enquanto os usuários de planos individuais/familiares de assistência médica tiveram suas mensalidades majoradas no máximo em 13,55\%, em 2017 , conforme teto determinado pela ANS, a maioria das operadoras $(58,72 \%)$ aplicaram reajustes maiores aos beneficiários vinculados a contratos coletivos com até 30 vidas, chegando a serem informados percentuais superiores a $40 \%$ por seis delas (CB Saúde, Unimed de Fernandópolis, Unimed Ariquemes, Unimed Agreste Meridional, Santa Casa de São José do Rio Pardo, Unimed Regional Floriano). Nesses contratos, algumas operadoras de grande porte, como Bradesco, Amil, Notre Dame e Sul América, aplicaram reajustes superiores a 17\% (30). Assim, apesar de apresentarem mensalidades iniciais mais baixas, em relação aos planos individuais, os planos coletivos podem se tornar muito caros, a médio e longo prazo, dada a aplicação de reajustes superiores.

Outro fator que torna os planos coletivos mais vendáveis e interessantes para o público é que, em algumas circunstâncias delineadas pela RN no 195/2009, eles são comercializados com a isenção dos prazos de carências e dos períodos de cobertura parcial para doenças preexistentes. (9)

As parcerias entre operadoras e administradoras de benefícios também têm contribuído para o incremento dos planos coletivos, já que as administradoras conseguem ampliar a carteira de clientes, principalmente dos planos coletivos por adesão, recorrendo ao marketing de "panfletagem" e aos acordos com sindicatos, associações profissionais, entidades estudantis e conselhos de classe. (31) (32) 
A não-comercialização de planos individuais ou a oferta de planos mais restritos geograficamente também pode ser uma estratégia de redução de risco das operadoras, pois, se elas oferecerem planos individuais/familiares de abrangência nacional, estarão mais sujeitas a receberem, através da portabilidade de carências, clientes idosos ou portadores de patologias graves, sem a possibilidade de aplicar novos prazos de carência para a utilização de seus serviços ${ }^{5}$. (33)

Outro elemento que pode ter colaborado para a concentração do mercado de planos individuais nas mãos de poucas empresas, foi a "quebra", nos últimos anos, de algumas operadoras do sistema Unimed, que concentravam uma carteira significativa de consumidores desse tipo de produto, a exemplo da Unimed Paulistana, Unimed Brasília e da Unimed São Luís. (34)

As consequências dessas transformações no mercado, para os consumidores, são a redução nas possibilidades de contratação de um plano individual/familiar, sobretudo de abrangência nacional, e o prejuízo ao direito à portabilidade de carências, pois, dada a falta de opções, eles enfrentam obstáculos para mudar de operadora, ainda que estejam dispostos a pagar altas mensalidades, conforme tem sido amplamente noticiado na mídia. (35) (36) (37) (38)

Grande parte das reportagens selecionadas pela pesquisa retratam os impactos do problema para os consumidores que, ante à dificuldade para contratar um plano de saúde individual mais completo e à falta de vínculo empregatício ou classista/associativo/sindical para a contratação de um plano coletivo, acabam recorrendo a clínicas populares para obterem consultas e exames a preços mais baixos, ou adquirem planos individuais com grandes restrições de rede credenciada (prestadores periféricos, ou atendimento exclusivo em hospitais próprios), limitações de abrangência geográfica, altos percentuais de coparticipação ou franquia. (39) (34) (40)

As matérias também evidenciam a contratação de produtos com segmentação exclusivamente ambulatorial que, apesar de serem autorizados pela Lei no 9.656/98, fragmentam o cuidado com o paciente, por não contemplarem a cobertura obstétrica nem a realização de procedimentos que requeiram internação hospitalar (34) (39). Atualmente,

\footnotetext{
${ }^{5}$ A RN 186/2009 trata dos critérios para a realização da portabilidade de carências pelos beneficiários de planos de saúde. Há menos exigências para os beneficiários de planos individuais, mas a flexibilização da norma, para facilitar a portabilidade dos usuários de planos coletivos, está em análise, após conclusão do processo de consulta pública n 63 , realizada pela ANS.
} 
3,98\% dos beneficiários de planos individuais possuem esse tipo de produto, de acordo com os dados da Sala de Situação da ANS. (14)

A oferta deficiente de planos individuais também pode impedir o direito de permanência dos usuários na mesma operadora, na hipótese de o contrato coletivo ser encerrado por ela (41), e dificultar o acesso de idosos ou portadores de alguma patologia grave ou crônica (42), já que, apesar da proibição legal (4), esses consumidores acabam sendo "evitados" pelas operadoras, fato frequentemente denunciado nos jornais (35) (37) (42). Por um lado, a maioria desses consumidores está fora do mercado de trabalho e não possui vínculos com entidades contratantes de planos coletivos (42) (36) (38). Por outro, quando encontram planos individuais que os atendam, os preços iniciais são elevados e até proibitivos. (38) (43)

O problema adquiriu tamanha relevância social, que vem sendo amplamente debatido no Congresso Nacional, no âmbito das discussões sobre a alteração da Lei oํ 9.656/98 (PL № 7.419/2016 e PLS no 76/2017) (44) (45). Dentre as propostas incluídas para votação na Câmara dos Deputados, está a obrigatoriedade de que todas as operadoras de planos privados (exceto as autogestões) comercializem plano individual de saúde (44). E, no Senado, propõe-se, inclusive, a imposição de um teto único, pela ANS, para o reajuste de planos individuais e coletivos. (45)

Porém, essas medidas talvez não resultem em maiores possibilidades de escolha ao consumidor, pois os altos preços podem continuar funcionando como barreiras à contratação de planos individuais.

Alguns grupos de pressão argumentam que a diminuição das coberturas obrigatórias tornariam esses planos mais acessíveis (44), mas a comercialização de planos individuais com valores mais baixos pode ser viabilizada sem retrocessos em relação aos direitos assistenciais e sem prejuízos ao direito à saúde dos usuários, a partir de ações que representem ganho de eficiência para o setor, como: a) implantação de fluxos e relações mais transparentes na aquisição de materiais (órteses e próteses); b) hierarquização do atendimento básico; c) expansão de programas que incentivem a adoção de estilos de vida saudáveis, pelos usuários, a promoção da saúde e a prevenção de doenças; d) maior qualificação da rede assistencial; e) adoção de novos modelos de remuneração aos prestadores de serviço em saúde, que priorizem os resultados e não a quantidade de 
procedimentos; f) uso em maior escala de planos com fator moderador (coparticipação e franquia), como forma de desestimular o uso desnecessário dos serviços. (11) (44)

\section{Conclusão}

O estudo confirmou, parcialmente, a hipótese inicial de que a redução na oferta de planos individuais seria uma resposta do próprio mercado de saúde suplementar à maior regulação governamental.

Certamente, as "proteções" conferidas pela lei e pela regulamentação infralegal aos beneficiários de planos individuais, em detrimento dos usuários de planos coletivos - 0 controle de reajuste e a impossibilidade de cancelamento unilateral injustificado dos contratos - tornou aqueles produtos menos interessantes para as operadoras setoriais, cujo comportamento é orientado por uma "lógica empresarial e industrial". (46)

Todavia, não se pode ignorar a confluência de outros fatores, como: a gênese da assistência suplementar à saúde que, no Brasil, deu-se em torno do vínculo trabalhista; a relação entre o crescimento do mercado de planos coletivos e o aumento do nível de emprego formal; a disponibilização de planos de saúde pelas empresas como uma política de pessoal; as decisões e não decisões políticas que permitiram a consolidação de um discurso de responsabilização das empresas e até mesmo dos órgãos públicos, pelo patrocínio de planos de saúde para seus empregados ou servidores; o desenvolvimento de estratégias, pelas operadoras, de ampliação de seus mercados, como a angariação de clientes por administradoras e a celebração de contratos coletivos com pequenos grupos; a não-oferta de planos individuais com abrangência nacional pelas operadoras como forma de evitar a absorção de clientes idosos por portabilidade de carências; os incentivos tributários às empresas que ofertam plano coletivo aos seus funcionários; e, por fim, o menor custo dos planos coletivos, em razão da menor incidência de idosos e da possibilidade de ganhos em escala, pelas operadoras.

As principais consequências desse fenômeno são o prejuízo ao poder de escolha da população, a falta de mobilidade dos beneficiários entre as operadoras (dificuldade de exercer a portabilidade), e a inviabilidade de contratação desse tipo de produto em municípios onde não existe sua comercialização - fatos que afetam diretamente o direito à saúde. 
A atuação do Congresso Nacional nessa matéria retrata o quão importante ela se tornou para a sociedade. Todavia, as alterações que têm sido pensadas talvez não sejam suficientes para solucionar o problema da baixa oferta de planos individuais, pois os altos preços podem continuar impedindo a sua contratação.

Considerando que o papel da regulação da saúde suplementar é zelar pelo interesse público, garantindo o equilíbrio setorial e protegendo os direitos dos consumidores, que são os atores mais frágeis nesse mercado, faz-se necessário desenvolver outros estudos para aprofundar a investigação sobre esse fenômeno, bem como buscar possíveis soluções que não resultem na perda de direitos já consagrados ou na piora da qualidade assistencial aos beneficiários.

\section{Referências}

1. Menicucci TMG. Público e privado na política de assistência à saúde no Brasil: atores, processos e trajetória. Rio de Janeiro: Editora Fiocruz, 2007.

2. Brasil. Constituição da República Federativa do Brasil, 8 de outubro de 1988. Brasília: Senado Federal, 2008.

3. Nitão SRV. Saúde suplementar no Brasil: um estudo da dinâmica industrial pósregulamentação. Rio de Janeiro: Programa de Pós-Graduação em Ciências na área da saúde pública, Escola Nacional de Saúde Pública Sergio Arouca; 2004. Disponível em: http://thesis.icict.fiocruz.br/pdf/nitaosrvm.pdf [Acesso em 2.ago.2017].

4. Brasil. Lei no 9.656, 3 de junho de 1998. Dispõe sobre os planos e seguros privados de assistência à saúde. Disponível em: http://www.planalto.gov.br/Ccivil 03/leis/L9656.htm [Acesso 10.ago.2017]

5. Brasil. Lei no 9.961, 28 de janeiro de 2000. Cria a Agência Nacional de Saúde Suplementar - ANS e dá outras providências. Disponível em: http://www.planalto.gov.br/Ccivil 03/leis/L9961.htm [Acesso 10.ago.2017]

6. Brasil. Lei no 8.078, 11 de setembro de 1990. Dispõe sobre a proteção do consumidor e dá outras providências. Disponível em http://www.planalto.gov.br/ccivil 03/leis//8078.htm [Acesso 10.ago.2017]

7. Filho LTP. Dossiê saúde pública - Iniciativa privada e saúde. Estudos Avançados USP. 1999; 13(35):109-116. Disponível em:

http://www.scielo.br/scielo.php?script=sci arttext\&pid=S0103-40141999000100011

[Acesso em 11.ago.2017].

8. Agência Nacional de Saúde Suplementar. Formas de contratação de planos de saúde. Rio de Janeiro, 2017. Disponível em: http://www.ans.gov.br/planos-de-saude-e- 
operadoras/contratacao-e-troca-de-plano/dicas-para-escolher-um-plano/formas-decontratacao-de-planos-de-saude [Acesso em 2.ago.2017].

9. Agência Nacional de Saúde Suplementar. Resolução Normativa no 195 de 14 de julho de 2009. Dispõe sobre a classificação e características dos planos privados de assistência à saúde. Disponível em:

http://www.ans.gov.br/component/legislacao/?view=legislacao\&task=TextoLei\&format=raw \&id=MTQ1OA [Acesso em 4.ago.2017].

10. Cruz A, Mendes EV (org.) CONASS Debate. Saúde: para onde vai a nova classe média. Brasília: CONASS, 2013.

11. Cechin J. Saúde: para onde vai a nova classe média. In: CONASS Debate. Brasília: CONASS, 2013.

12. Gerhardt TE, Silveira DT (org). Métodos de Pesquisa. Porto Alegre: UFRS, 2009. Disponível em: http://www.ufrgs.br/cursopgdr/downloadsSerie/derad005.pdf [Acesso em 14.out.2017].

13. Agência Nacional de Saúde Suplementar. Caderno de Informações da Saúde Suplementar - 06/2017. Disponível em:

http://www.ans.gov.br/images/stories/Materiais para pesquisa/Perfil setor/Caderno inform acao saude suplementar/caderno informacao junho 2017.pdf [Acesso em 2.ago.2017].

14. Agência Nacional de Saúde Suplementar. Sala de situação. Disponível em: http://www.ans.gov.br/perfil-do-setor/dados-e-indicadores-do-setor/sala-de-situacao [Acesso em 4.out.2017].

15. Agência Nacional de Saúde Suplementar. Caderno de Informações da Saúde Suplementar - 01/2007. Disponível em:

http://www.ans.gov.br/images/stories/Materiais para pesquisa/Perfil setor/Caderno inform acao saude suplementar/2007 mes03 caderno informacao.pdf [Acesso em 2.ago.2017].

16. Agência Nacional de Saúde Suplementar. Atlas Econômico Financeiro da Saúde Suplementar 2016. Disponível em:

http://www.ans.gov.br/images/stories/Materiais para pesquisa/Perfil setor/Atlas/2016 atla s.pdf [Acesso em 9.out.2017].

17. Agência Nacional de Saúde Suplementar. Dados e planos da operadora. Disponível em: http://www.ans.gov.br/planos-de-saude-e-operadoras/informacoes-e-avaliacoes-deoperadoras/consultar-dados [Acesso em 17.set.2017].

18. Agência Nacional de Saúde Suplementar. Nota sobre levantamento divulgado pelo IDEC. Disponível em: http://www.ans.gov.br/a-ans/sala-de-noticias-ans/consumidor/2554nota-da-agencia-nacional-de-saude-suplementar-ans [Acesso em 2.out.2017].

19. Catapreta HLNC. Análise da política de reajuste para planos individuais e coletivos implementada pela ANS. Revista Brasileira de Risco e seguro. 2004; 1(0):21-46.

Disponível em: http://www.rbrs.com.br/arquivos/rbrs 0 2.pdf [Acesso em 2.ago.2017] 
20. Agência Nacional de Saúde Suplementar. Regras de reajuste. Disponível em: http://www.rbrs.com.br/arquivos/rbrs 0 2.pdfhttp://www.ans.gov.br/index.php/a-ans/salade-noticias-ans/consumidor/1793-ans-define-regras-de-reajuste-para-planos-coletivoscom-menos-de-30-beneficiarios [Acesso em 2.ago.2017].

21. Agência Nacional de Saúde Suplementar. Resolução Normativa no 309 de 24 de outubro de 2012. Dispõe sobre o agrupamento de contratos coletivos para fins de cálculo de reajuste. Disponível em:

http://www.ans.gov.br/component/legislacao/?view=legislacao\&task=TextoLei\&format=raw \&id=Mjl4Mg [Acesso em 2.set.2017].

22. Instituto Brasileiro de Defesa do Consumidor. Carta IDEC no 117/2015 - Reajuste de planos individuais/familiares. Disponível em: http://www.idec.org.br/pdf/2015-06-11-cartaidec-117-Coex.pdf [Acesso em 13.ago.2017].

23. Agência Nacional de Saúde Suplementar. Nota 1241/2014/GGEFP/DIPRO/ANS. Disponível em:

http://www.ans.gov.br/images/stories/A ANS/Transparencia Institucional/agenda regulator ia/NOTA PRICECAP.pdf [Acesso em 2.ago.2017].

24. Silva OJB. E o Sistema Único de Saúde-SUS para os pobres? Cadernos Ibero americanos de Direito Sanitário. 2017; 6(2):180-192. Disponível em:

http://www.cadernos.prodisa.fiocruz.br/index.php/cadernos/article/view/391/464 [Acesso em 30.set.2017].

25. Mata BRR. Impacto financeiro de 2010 a 2030 do envelhecimento dos beneficiários em operadoras de plano de saúde de Minas Gerais: um estudo de caso. Belo Horizonte: Programa de Pós-Graduação em Demografia, Universidade Federal de Minas Gerais; 2011. Disponível em: https://www.ufmg.br/online/arquivos/anexos/planos sa\%FAde.pdf [Acesso em 4.ago.2017].

26. Reis COO. Texto para discussão nำ 1167. Novos modelos de gestão na saúde privada. Rio de Janeiro: IPEA; 2006. Disponível em: http://www.ipea.gov.br/portal/index.php?option=com content\&view=article\&id=4336 [Acesso em 4.ago.2017].

27. Instituto Brasileiro de Defesa do Consumidor. Sem plano. In: Revista idec. 2016; 207. Disponível em: https://www.idec.org.br/em-acao/revista/direitos-pelosares/materia/sem-plano [Acesso em 21.ago.2017].

28. Formenti, L. $40 \%$ dos planos falsos coletivos têm reajuste acima do teto fixado pela ANS. Estadão. 9 set 2017. Disponível em: http://saude.estadao.com.br/noticias/geral,40por-cento-dos-planos-falsos-coletivos-tem-reajuste-acima-do-teto-fixado-pelaans,70001978906 [Acesso em 16.set.2017].

29. Instituto Brasileiro de Defesa do Consumidor. Nove anos após a Lei no 9.656/98. Revista CREMESP. 2010; 238:7-14. Disponível em: http://www.cremesp.org.br/?siteAcao=Jornal\&id=852 [Acesso em 2.ago.2017]. 
30. Agência Nacional de Saúde Suplementar. Reajustes aplicados pelas operadoras para contratos coletivos com até 30 beneficiários. Disponível em:

http://www.ans.gov.br/planos-de-saude-e-operadoras/espaco-do-consumidor/reajustes-deprecos-de-planos-de-saude/reajustes-aplicados-pelas-operadoras-para-contratos-coletivoscom-ate-30-beneficiarios [Acesso em 4.out.2017].

31. Instituto Brasileiro de Defesa do Consumidor. A falsa coletivização de contratos nos planos de saúde. Disponível em: https://www.idec.org.br/em-acao/artigo/a-falsacoletivizaco-de-contratos-nos-planos-de-saude [Acesso em 2.ago.2017].

32. Agência Nacional de Saúde Suplementar. Resolução Normativa no 196 de 14 de julho de 2009. Dispõe sobre a administradora de benefícios. Rio de Janeiro. Disponível em: http://www.ans.gov.br/component/legislacao/?view=legislacao\&task=TextoLei\&format=raw \&id=MTQ1OQ [Acesso em 4.ago.2017].

33. Agência Nacional de Saúde Suplementar. Resolução Normativa no 186 de 14 de janeiro de 2009. Dispõe sobre a regulamentação da portabilidade das carências.

Disponível em:

http://www.ans.gov.br/component/legislacao/?view=legislacao\&task=TextoLei\&format=raw \&id=MTM4OQ [Acesso em 13.ago.2017].

34. Costa R, Ferrari H. Quebra de planos de saúde força consumidor a aceitar convênio pior. Correio Braziliense. 17 jul 2016. Disponível em:

http://blogs.correiobraziliense.com.br/vicente/quebra-de-planos-de-saude-forcaconsumidor-a-aceitar-convenio-pior/ [Acesso em 21.ago.2017].

35. Laporta T. Idosos doentes enfrentam recusa ao tentar trocar plano de saúde. G1. 11 set 2016. Disponível em: http://g1.globo.com/economia/noticia/2016/09/idosos-e-doentesenfrentam-recusa-ao-tentar-trocar-plano-de-saude.html [Acesso em 4.out.2017].

36. Folha PE. Economia: planos de saúde tornam-se "artigos de luxo" no Brasil. Portal Nova Mais. 05 jun 2016. Disponível em: http://novamais.com/noticias/10429/economiaplanos-de-saude-tornam-se-artigos-de-luxo-no-brasil [Acesso em 04.ago.2017].

37. Clientes têm dificuldades para conseguir plano de saúde individual. Bom dia Brasil, G1. 05 ago 2016. Disponível em: http://g1 globo.com/bom-diabrasil/noticia/2016/08/clientes-tem-dificuldades-para-conseguir-plano-de-saudeindividual.html [Acesso em 04.ago.2017].

38. Biderman I. Convênios individuais minguam. Folha UOL. 17 jun 2016. Disponível em: http://www1.folha.uol.com.br/seminariosfolha/2016/06/1782523-convenios-individuaisminguam-usuarios-ficam-refens-de-ofertas-caras.shtml [Acesso em 4.ago.2017].

39. Villela F. Planos de saúde perdem 1,3 milhão de clientes em um ano. EBC Agência Brasil. 02 maio 2016. Disponível em: http://agenciabrasil.ebc.com.br/geral/noticia/2016-05/planos-de-saude-perdem-13-milhaode-clientes-em-um-ano [Acesso em 4.ago.2017]. 
40. Instituto Brasileiro de Defesa do Consumidor. Planos de saúde baratos têm rede de atendimento reduzida. 23 maio 2017. Disponível em: https://www.idec.org.br/o-idec/salade-imprensa/release/planos-de-saude-baratos-tem-rede-de-atendimento-reduzida-apontapesquisa-do-idec [Acesso em 16.set.2017].

41. Conselho de Saúde Suplementar. Resolução CONSU no 19 de 25 de março de 1999. Dispõe sobre a absorção de consumidores pelas operadoras que operam planos coletivos que vierem a ser liquidados ou encerrados. Disponível em:

http://www.ans.gov.br/component/legislacao/?view=legislacao\&task=TextoLei\&format=raw \&id=Mjg3 [Acesso em 13.ago.2017].

42. Dino. Idosos são proibidos de fazer plano de saúde mesmo pagando $500 \%$ a mais. Terra. 31 maio 2017. Disponível em: https://www.terra.com.br/noticias/dino/idosos-saoproibidos-de-fazer-plano-de-saude-mesmo-pagando-500-amais,cc2584cfa1d8f22e5979a9d189a71358eu9lvccr.html [Acesso em 3.set.2017].

43. Contratação de planos de saúde fica cada vez mais difícil. O Globo. 03 jul 2017. Disponível em: https://oglobo.globo.com/economia/defesa-do-consumidor/contratacao-deplanos-de-saude-fica-cada-vez-mais-dificil-diz-idec-21545308 [Acesso em 5.set.2017].

44. Brasil. Projeto de Lei no 7.419 de 9 de agosto de 2006. Dispõe sobre a alteração da Lei 9.656/98. Brasília. Disponível em:

http://www.camara.gov.br/proposicoesWeb/fichadetramitacao?idProposicao=332450 [Acesso em 24.out.2017].

45. Brasil. Projeto de Lei do Senado no 76 de 29 de março de 2017. Dispõe sobre a alteração da Lei 9.656/98. Disponível em:

https://www25.senado.leg.br/web/atividade/materias/-/materia/128532 [Acesso em 29.out.2017].

46. Costa, LS et al. Análise do subsistema de serviços em saúde na dinâmica do complexo econômico-industrial da saúde. In: Fundação Oswaldo Cruz. A saúde no Brasil em 2030. Rio de Janeiro: Fiocruz/Ipea/Ministério da Saúde/Secretaria de Assuntos Estratégicos da Presidência da República. 2013. Disponível em: http://books.scielo.org/id/scfy6/pdf/noronha-9788581100197-06.pdf [Acesso em 30.set.2017]. 